\title{
PENGARUH BLENDED LEARNING BERBASIS ROTATION MODEL TERHADAP MOTIVASI DAN HASIL BELAJAR GEOGRAFI SISWA MA MATHOLIUL ANWAR LAMONGAN
}

\section{Moh Munzadi}

Prodi Pendidikan Geografi, Universitas Pendidikan Ganesha, Indonesia

\section{A R T I C L E I N F O}

Article history:

Received 10 Agustus 2018

Received in revised form

16 November 2018

Accepted 12 November 2018

Available online 30

November 2018

\section{Kata Kunci:}

Blended Learning, Rotation

Model, Quasi Eksperiment

Keywords:

Blended Learning, Rotation

Model, Quasi Eksperiment

1,674, pada taraf signifikan $5 \%$ kemudian Hasil belajar di eksperimen lebih tinggi dari kelas kontrol secara meyakinkan dengan nilai $\boldsymbol{t}_{\text {hitung }}$ lebih besar dibandingkan nilai $\boldsymbol{t}_{\text {tabel }}$ yaitu $3.8419>1,674$ pada taraf signifikansi $5 \%$.

\section{A B S T R A C T}

This research purposes to determine the differences between motivation and achievement of geography learning outcomes between before and after using the Blended Learning based Rotation Model. The research design uses Quasi Experiment with the Non-Equivalent Control Group Design technique, the method of data collection uses the method of recording documents, questionnaires and tests, which are then analyzed using a different test ( $t$-test). This research was conducted in class $X$ MA. Matholiul Anwar Simo Sungelebak Karanggeneng Lamongan. The results showed that there were differences in motivation and student learning outcomes between classes given treatment using a Rotated Model-based Blended Learning model with a control class that was not treated. Motivation in the experimental class is higher than the control class convincingly with a value greater than the value of $5.1815>1.674$, at a significant level of $5 \%$ then the learning outcomes in the experimental class are higher than the control class convincingly with a value greater than the value ie $3.8419>1.674$ at a significance level of $5 \%$.

\section{Pendahuluan}

Geografi dalam kurikulum pendidikan nasional yang berlaku saat ini (Kurikulum 2013 Edisi Revisi) diajarkan kepada siswa di sekolah pada jenjang pendidikan dasar dan menengah, proses pembelajarannya berbeda pada setiap jenjang pendidikan. Geografi pada jenjang pendidikan SD dan SMP, diajarkan secara terintegrasi dengan mata 
pelajaran lainnya yang termasuk kelompok Ilmu Sosial, dengan nama mata pelajaran Ilmu Pengetahuan Sosial (IPS). Seperti halnya pada jenjang pendidikan dasar, di Sekolah Menengah Kejuruan (SMK) geografi juga diajarkan secara terintegrasi dengan mata pelajaran kelompok Ilmu Sosial lainnya dengan nama mata pelajaran IPS. Berbeda halnya pada jenjang Sekolah Menengah Atas (SMA), geografi diajarkan secara tersendiri sebagai satu mata pelajaran.

Penggunaan media pembelajaran geografi dalam proses pembelajaran dapat meningkatkan respon siswa untuk memahami materi geografi yang bersifat abstrak, karena siswa seolah diajak untuk berhadapan dengan objek yang sebenarnya. Tampilan dari media geografi bersifat dinamis sehingga tidak memberikan rasa bosan dan jenuh bagi siswa (Syahrudin, 2015). Penjabaran konsep dan pokok bahasan geografi dalam pelaksanaan pembelajarannya di sekolah harus disesuaikan dan diserasikan dengan tingkat pengalaman serta perkembangan mental anak sesuai jenjang pendidikannya. Berkenaan dengan itu dalam pembelajarannya diperlukan kesiapan guru untuk melakukan seleksi terhadap materi pengajaran dan pendekatan serta metode yang dipergunakan. Tujuanya, agar siswa memperoleh pengetahuan geografi sesuai tingkatan usia pada setiap jejang pendidikan, dengan kata lain pengajaran geografi dilakukan secara bertahap sesuai dengan tahapan perkembangan usia siswa. Guru dapat menumbuhkan motivasi siswa melalui pembelajaran yang efektif. Salah satu komponen penting dalam penyusunan rencana pembelajaran yang efektif adalah penggunaan metode atau model pembelajaran yang tepat dan bervariasi (Hanifah dan Pargito, 2013)

Utami (2017) menjelaskan bahwa Pada proses belajar bagi peserta didik tidak hanya berinteraksi dengan guru sebagai salah satu sumber belajar tetapi berinteraksi pula dengan keseluruhan sumber belajar yang digunakan sebagai bagian dalam pencapaian tujuan pembelajaran Kelangsungan pembelajaran agar berjalan dengan maksimal membutuhkan komponen-komponen pendukung yang sekaligus mencirikan terjadinya interaksi pembelajaran tersebut. Komponen dimaksud adalah (1) tujuan yang ingin dicapai, (2) bahan/pesan yang menjadi isi interaksi, (3) peserta didik yang aktif mengalami proses pembelajaran, (4) guru yang melaksanakan proses pembelajaran, (5) metode untuk mencapai tujuan pembelajaran, (6) situasi yang memungkinkan proses pembelajaran berjalan dengan baik, dan (7) penilaian terhadap hasil interaksi dalam proses pembelajaran (Hanafy, 2014). Secara khusus guru geografi yang profesional di tuntut tindakan inovatif agar peserta didik menguasai kompetensi yang diharapkan. Seorang guru geografi profesional harus mempunyai pengetahuan yang luas dan mendalam dalam mengorganisir materi pelajaran sesuai Standar Isi (Kurikulum) melalui pendekatan keruangan, pendekatan ekologi, dan pendekatan kompleks wilayah. Penguasaan pengetahuan ini merupakan syarat yang penting di samping keterampilanketerampilan lainnya. Oleh sebab itu seorang guru dituntut dapat menciptakan (membangun) proses berfikir serta dapat membantu tumbuhnya sikap kritis siswa melalui serangkaian tindakan inovatif (Lubis, 2011).

Dalam Proses pembelajaran Geografi (IPS), seorang guru memiliki peran penting dalam menyampaikan informasi, melatih keterampilan dan membimbing 
belajar siswa sehingga para guru dituntut memiliki kualifikasi dan kompetensi tertentu, agar proses belajar dan pembelajaran dapat berlangsung efektif dan efisien (Latief, 2014). Realita yang terjadi di lapangan menunjukkan terdapat permasalahan yang dijumpai dalam pembelajaran geografi di sekolah. Beberapa penelitian menemukan suatu permasalahan yang sama pada mata pelajaran geografi, yaitu rendahnya pemahaman siswa terhadap materi pelajaran geografi. Hal ini dinilai penyebabnya didominasi oleh metode ceramah yang digunakan guru dengan pembelajaran yang berpusat pada guru. Hal ini menyebabkan 4C (Critical Thinking, Communication, Collaboration, dan Creativity) yang menjadi karakter pembelajaran Abad 21 tidak berkembang dalam pembelajaran geografi. Selain masih rendahnya ketuntasan belajar, motivasi dan hasil belajar siswa juga masih rendah, dari hasil pengamatan peneliti terlihat masih kurangnya persiapan siswa ketika waktu pelajaran produktif (Sjukur, 2012).

Pembelajaran geografi di MA Matholi'ul Anwar juga menunjukkan permasalahan yang tidak jauh berbeda. Hasil wawancara dengan guru mata pelajaran geografi pada tanggal 22 s/d 30 januari 2018 menunjukkan bahwa permasalahan utama yang di hadapi adalah rendahnya pemahaman siswa terhadap materi geografi. Guru menyadari bahwa penyebab dari permasalahan tersebut adalah metode yang digunakan selama ini, yaitu ceramah, sehingga kreatifitas dan aktifas siswa dalam pembelajaran, terutama dalam menyampaikan pendapat menjadi tidak berkembang. Disuatu pihak pekerjaan sebagai guru akan memperoleh penghargaan yang lebih tinggi, tetapi difihak lain pengakuan tersebut mengharuskan guru memenuhi sejumlah Pengaruh persyaratan agar mencapai standar minimal seorang profesional (Wulandari, 2013). Hal tersebut berpengaruh terhadap hasil belajar siswa. Hasil belajar geografi di Kelas X di MA Matholi'ul Anwar, rata-ratanya hanya mencapai 60 (enam puluh). Pencapaian hasil belajar geografi tersebut masih perlu ditingkatkan, karena masih berada di bawah Kriteria Ketuntasan Minimal (KKM), yaitu 75.

Berdasarkan permasalahan yang telah dikemukakan tersebut diujicobakan model pembelajaran Blended Learning berbasis Rotation Model, sehingga pemahaman siswa serta keaktifan siswa dalam menyampaikan pendapat meningkat dan hasil belajar siswa juga meningkat. Blended Learning mengacu pada belajar yang mengkombinasi atau mencampur antara pembelajaran tatap muka (face to face learning) dan pembelajaran berbasis komputer (computer based learning).

Peningkatan pemahaman siswa serta keaktifan siswa dalam menyampaikan pendapat yang kemudian berimplikasi terhadap hasil belajar siswa juga meningkat melalui Blended Learning berbasis Rotation Model karena adanya beberapa kenggulan yang dimiliki. Syahrin (2015) mengemukakan beberapa keunggulan Blended Learning, yaitu; (1) peserta didik leluasa untuk mempelajari materi pembelajaran secara mandiri dengan memanfaatkan materi-materi yang tersedia secara online, (2) peserta didik dapat melakukan diskusi dengan pengajar atau peserta didik di luar tatap muka, (3) kegiatan pembelajaran yang dilakukan peserta didik di luar jam tatap muka dapat dikelola dan dikontrol dengan baik oleh pengajar, (4) pengajar dapat meminta peserta didik membaca materi atau mengerjakan tes yang dilakukan sebelum pembelajaran (5) 
pengajar dapat menambahkan materi pengayaan melalui fasilitas internet, (6) pengajar dapat menyelenggarakan kuis, memberikan balikan, dan memanfaatkan hasil tes dengan efektif, (7) peserta didik saling berbagi file dengan siswa lain. Rahayu (2015)Mengungkapkan bahwa Hasil dari proses belajar tidak hanya berupa pemahaman atas konsepkonsep, akan tetapi yang lebih penting adalah aplikasinya dalam kehidupan sehari-hari di dalam masyarakat

Keunggulan tersebut diharapkan siswa dapat aktif dalam pembelajaran tatap muka maupun pembelajaran secara online. Peningkatan aktifitas siswa dalam pembelajaran melalui Blended Learning dinilai akan dapat meningkatkan pemahaman siswa serta kreatifitas siswa dalam mengomunikasikan pemikirannya karena konsep materi yang dipelajari dapat dipahami melalui pembelajaran yang inovatif dan kreatif. Selain itu dengan Blended Learning siswa akan mampu aktif didalam proses pembelajaran melalui fasilitas yang disediakan pada platfrom online, seperti forum dan diskusi online, baik dengan menggunakan edmodo dan email sebagai aplikasi pembelajaran jarak jauh.

Berdasarkan uraian tersebut, sistem pembelajaran Blended Learning diasumsikan berpengaruh positif terhadap hasil belajar Geografi siswa. Materi Geografi yang banyak dan waktu belajar di sekolah yang sedikit, dengan tersedianya fasilitas komputer dan jaringan internet maka Blended Learning dinilai sesuai untuk pembelajaran geografi. Berkenaan dengan itu, dilaksanakan suatu penelitian yang berjudul "Pengaruh Blended Learning Berbasis Rotation Model terhadap Hasil Belajar Geografi Siswa Kelas X MA Matholiul anwar Tahun Pelajaran 2018/2019”.

Penelitian ini bertujuan untuk menganalisis perbedaan motivasi belajar geografi siswa yang belajar menggunakan model Blended Learning dengan yang tidak. Selain itu juga untuk menganalisis perbedaan hasil belajar geografi siswa yang belajar menggunakan model Blended Learning dengan yang tidak.

\section{Metode}

Penelitian ini menggunakan desain penelitian Quasi Eksperimen dengan teknik Non-Equivalent Control Grup Design. Desain penelitian ini dimulai dengan terlebih dahulu menentukan kelompok eksperimen dan kelompok kontrol, kemudian kelompok tersebut diberikan perlakuan yang berbeda kelompok eksperimen diberi Blended Learning kelompok kontrol tidak, setelah itu kedua kelompok sama-sama diberikan tes akhir untuk melihat apakah ada pengaruh dari perlakuan. Objek dalam penelitian adalah pembelajaran blended learning berbasis rotation model sedankan subjek penelitian adalah siswa kelas X MA Matholiul Anwar.

Sampel dalam penelitian diambil dengan Purposive Sampling. Teknik ini digunakan karena sampel yang diambil berdasarkan maksud dan tujuan tertentu, yaitu untuk menentukan sampel yang memiliki kualitas yang hampir sama antara kelompok eksperimen dengan kelompok kontrol. Sehingga perbedaan hasil penelitian yang di dapat adalah akibat dari suatu perlakuan.

Data yang dikumpulkan dalam penelitian adalah data primer dan sekunder. Data primer berupa:(1) skor motivasi belajar siswa yang di peroleh dari angket atau 
kuesioner (2) nilai hasil belajar geografi yang diperoleh dari hasil pre test sebelum perlakuan diberikan; (3) nilai hasil belajar geografi yang diperoleh dari post test setelah model Blanded Learning dilakukan, yang semuanya bersumber dari Siswa Kelas X MA Matholiul Anwar. Data sekunder merupakan data tentang jumlah siswa yang akan dijadikan subjek penelitian yang bersumber dari Registrasi Sekolah.

Memperhatikan data yang dibutuhkan dalam penelitian ini, metode pengumpulan data yang digunakan adalah: (1) Metode pencatatan dokumen data jumlah siswa dan kondisi masing-masing kelas X di MA Matholiul Anwar. (2) Metode kuesioner atau angket untuk memeperoleh data tentang motivasi belajar siswa. (3) Metode tes untuk mengumpulkan data hasil belajar geografi siswa sebelum dan sesudah penggunaan Blended Learning berbasis Rotation Model dalam pembelajaran geografi pada siswa kelas X MA Matholiul Anwar. Tes yang digunakan dalam penelitian ini adalah soal easy. Data dianalisis secara kuantitatif menggunakan uji beda ( $\mathrm{t}$-tes.)

\section{Hasil dan pembahasan}

Hasil penelitian di kelas X MA Matholiul anwar menunjukkan bahwa terdapat perbedaan motivasi belajar siswa antara kelas eksaperimen yang belajar menggunakan model Blended Learning berbasis Rotation Model dengan kelas kontrol yang tidak menggunkan Blended Learning berbasis Rotation Model. Hal ini dapat dibuktikan dengan hasil uji hipotesis untuk skor angket motivasi belajar siswa antara kelas eksperimen dan kontrol nilai $\boldsymbol{t}_{\text {hitung }}$ lebih besar dibandingkan nilai $\boldsymbol{t}_{\text {tabel }}$ yaitu $5.1815>1,674$, dengan taraf signifikasi $5 \%$, artinya terdapat perbedaan motivasi belajar siswa yang lebih tinggi antara kelas eksperimen yang belajar menggunakan model pembelajaran Blended Learning berbasis rotation model dengan kelas kontrol yang belajar menggunakan model pembelajaran konvensional.

Sebagaimana telah dikemukakan pada landasan teori bahwa model Blended Learning merupakan suatu model pembelajaran yang kaya akan variasi, serta melibatkan siswa lebih aktif pada saat pembelajaran. Model pembelajaran Blended Learning yang diterapkan dalam penelitian ini memiliki kelebihan antara lain, menyediakan pengalaman belajar yang lebih individual, mendukung dan mendorong pembelajaran mandiri dan kolaborasi, meningkatkan keterlibatan peserta didik dalam pembelajaran, menyediakan wadah untuk melatih keterampilan di luar kelas, memberikan fleksibelitas waktu belajar bagi peserta didik.

Kelebihan lain dari blended learning yaitu: (1) hemat waktu (2) pembelajaran lebih efektif dan efesien, (3) peserta didik mudah dalam mengakses materi pembelajaran, (4) peserta didik leluasa untuk mempelajari materi pembelajaran, (5) memanfaatkan materi-materi yang tersedia secara online, (6) peserta didik dapat melakukan diskusi dengan guru atau peserta didik lain di luar jam tatap muka, (7) pengajar tidak terlalu banyak menghabiskan tenaga untuk mengajar, (9) menambahkan materi pengayaan melalui fasiltas internet, (10) memperluas jangkuan pembelajaran/pelatihan, (11) hasil yang optimal serta menngkatkan daya tarik pembelajaran. Sehingga dengan blended learning siswa dapat termotivasi belajar dan 
tidak cepat merasa bosan pada saat pembelajaran. Sehingga siswa termotivasi belajar dan tidak cepat merasa bosan pada saat pembelajaran.

Motivasi belajar siswa yang menggunakan Blended Learning lebih baik dari motivasi bejar tanpa model pembelajaran Blended Learning. Hal tersebut dibuktikan dengan perhitungan uji t. Pada perhitungan uji-t didapat nilai t-hitung sebesar 0.1256 dan t-tabel sebesar 1.9944. yang artinya bahwa ada pengaruh media Blended Learning terhadap motivasi belajar siswa.

Begitu pula dengan hasil belajar di MA Matholiul Anwar menunjukkan terdapat perbedaan hasil belajar siswa. Hal ini dapat dibuktikan hasil uji hipotesi nilai posttest antara kelas eksperimen dan kelas kontrol diperoleh nilai $\boldsymbol{t}_{\text {hitung }}$ lebih besar dibandingkan nilai $\boldsymbol{t}_{\text {tabel }}$ yaitu $3.8419>1,674$, artinya terdapat perbedaan hasil belajar siswa yang lebih tinggi antara kelas eksperimen yang belajar menggunakan model pembelajaran Blended Learning berbasis rotation model dengan kelas kontrol yang belajar menggunakan model pembelajaran konvensional. Hal tersebut dikarenakan siswa yang belajar menggunakan model Blended Learning lebih aktif dan keratif dalam pembelajaran baik tatap muka maupun pembelajaran online, maka dari itu siswa yang belajar dengan Blended Learning mendapatkan hasil belajar yang lebih tinggi dari pada kelas yang belajar menggunakan model konvensional.

Sebagaimana telah dikemukakan pada landasan teori bahwa model Blended Learning merupakan suatu model pembelajaran yang lebih mengutamakan pembelajaran berpusat pada siswa, sehingga pada saat proses pembelajaran siswa lebih banyak terlibat aktif dan guru hanya sebagai fasilitator yang mengarahkan siswa dalam belajar. Hal tersebut berpengaruh pada meningkatnya hasil belajar siswa kelas eksperimen yang belajar menggunakan model Blended Learning berbasis Rotation Model.

Alasan yang memperkuat mengapa blended learning (face to face, online dan offline) lebih unggul khususnya pada pembelajaran pendidikan geografi dikarenakan blended learning memiliki kombinasi media dalam penyampaian pembelajaran sehingga dapat mengakomodasi berbagai perbedaan preferensi belajar siswa. Tidak ada satu metode penyampaian yang ideal bagi seluruh bentuk pembelajaran. Suatu mata pelajaran yang berbeda akan membutuhkan metode pembelajaran yang berbeda. Blended learning menghendaki para profesional pembelajaran untuk mengakomodasi preferensi belajar siswa agar lebih tepat khususnya bagi pembelajaran di kelas sebagai pusat pembelajaran. Suatu pendekatan di kelas yang terbaik bagi pembelajaran yang dikombinasikan dengan kepemimpinan instruktur terbaik dengan suatu metode tambahan dalam satu pembelajaran.

Faktor pendukung keberhasilan lainnya yakni pada proses pembelajaran siswa secara aktif melakukan kegiatan-kegiatan terintegrasi yang difasilitasi dengan komputer, dan media pembelajaran / CD Pembelajaran (offline). Sistem komputer (media interaktif) dapat menyampaikan pembelajaran secara individual dan langsung kepada siswa dengan cara berinteraksi langsung dengan mata pelajaran yang diprogramkan dalam komputer. Hal tersebut berpengaruh pada meningkatnya hasil 
belajar siswa kelas eksperimen yang belajar menggunakan model Blended Learning berbasis Rotation Model.

Hasil belajar siswa menggunakan model pembelajaran Blended Learning menunjukkan hasil belajar lebih baik dari hasil belajar tanpa model pembelajaran Blended Learning. Hal tersebut dibuktikan dengan hasil nilai t-hitung sebesar 0.5564 dan t-tabel sebesar 1.9944. maka disimpulkan $\mathrm{H}_{\mathrm{o}}$ ditolak dan $\mathrm{H}_{\mathrm{a}}$ diterima, yang artinya bahwa ada pengaruh media Blended Learning terhadap hasil belajar siswa.

\section{Simpulan dan saran}

Berdasarkan paparan hasil penelitian dan pembahasan dapat disimpulkan sebagai berikut.

1. Terdapat perbedaan motivasi belajar siswa antara kelas eksperimen yang belajar meggunakan model pembelajaran Blended Learning berbasis rotation model dengan kelas kontrol yang belajar menggunakan model pembelajaran konvensional pada kelas X IPS di MA Matholiul Anwar tahun pelajaran 2018/2019. Motivasi belajar di kelas eksperimen lebih tinggi dari pada motivasi belajar di kelas kontrol.

2. Terdapat perbedaan hasil belajar antara kelas eksperimen yang belajar meggunakan model pembelajaran Blended Learning berbasis rotation model dengan kelas kontrol yang belajar menggunakan model pembelajaran konvensional pada kelas X IPS di MA Matholiul Anwar tahun pelajaran 2018/2019. Hasil belajar di kelas eksperimen lebih tinggi dari pada hasil belajar di kelas kontrol.

Berdasarkan hasil penelitian maka di bawah ini adalah saran yang dapat disampaikan berkaitan dengan pemgaruh model pembelajaran Blended Learning berbasis rotation model.

1. Memperhatikan Blended Learning dalam pembelajaran geografi maka, disarankan kepada guru pengajar untuk menerapkan model Blended Learning sebagai salah satu alternative yang dapat di gunakan pada pembelajaran geografi.

2. Kepada peneliti lain disarankan untuk melakukan penelitian lanjutan mengenai Blended Learning yang mengkaji tentang pengelolaan dan pengawasan proses pembelajaran.

\section{Daftar Rujukan}

Hanafy. (2014). Konsep Belajar Dan Pembelajaran. Lentera Pendidikan, 7(1), 66-79. Hanifah dan Pargito. (2013). Pengembangan Model Pembelajaran Clam Shell Belajar pada Mata Pelajaran Geografi. Studi Sosial, 1(1).

Latief, H. dan D. R. (2014). PENGARUH PEMBELAJARAN KONTEKSTUAL TERHADAP HASIL BELAJAR (STUDI EKSPERIMEN PADA MATA PELAJARAN GEOGRAFI KELAS VII DI SMPN 4 PADALARANG). Pendidikan Geografi, 14(2).

Lubis, N. L. (2011). Memahami Dasar-dasar Konseling dalam Teori dan Praktek. Jakarta: 


\section{Kencana.}

Rahayu, H. A. dan S. S. (2015). UPAYA MENINGKATKAN MOTIVASI DAN HASIL BELAJAR GEOGRAFI MELALUI PENERAPAN MEDIA AUDIO VISUAL DENGAN METODE MIND MAP. GeoEco, 1(1), 10-17.

Sjukur, S. B. (2012). Pengaruh blended learning terhadap motivasi belajar dan hasil belajar siswa di tingkat SMK. Pendidikan Vokasi, 2(3).

Syahrin. (2015). Pengaruh Model Pembelajaran Blended Learning Terhadap Hasil Belajar Mata Pelajaran IPS Siswa Kelas 8 di SMPN 37 Jakarta. Uin Syarif Hidayatullah Jakarta, 1(2).

Syahrudin, dkk. (2015). HUBUNGAN PEMANFAATAN MEDIA PEMBELAJARAN GEOGRAFI DALAM PROSES PEMBELAJARAN DENGAN MINAT BELAJAR SISWA KELAS X SMA KORPRI BANJARMASIN. Pendidikan Geografi, 2(1), 13-28.

Utami, K. M. (2017). Penerapan Interactive Scrabble Game dalam Meningkatkan Perbendaharaan Glosarium Geografi Kelas 8 pada Kelas Akselerasi di SMP Negeri 3 Jember. Jatim, 5(3).

Wulandari, F. D. P. dan A. A. (2013). PENGARUH MODEL PEMBELAJARAN AKTIF MELALUI STRATEGI ROTATING TRIO EXCHANGE TERHADAP PRESTASI BELAJAR SISWA PADA SUB POKOK BAHASAN OPTIK GEOMETRIS KELAS VIII DI SMP NEGERI 30 SURABAYA. Inovasi Pendidikan Fisika, 2(3). 